\title{
Penerapan Strategi Flipped Classroom dengan Pendekatan Scientific dalam Pembelajaran Matematika pada Kelas XI SMKN 2 Padang Panjang
}

\author{
Usmadi ${ }^{1)}$, Ergusni ${ }^{2)}$ \\ 1) PAI Pascasarjana Universitas Muhammadiyah Sumbar \\ 2) FKIP Universitas Muhammadiyah Sumbar \\ usmadidttumanggung@gmail.com \\ ergusni12@gmail.com
}

\begin{abstract}
The issues in this study are how learning outcomes, learning motivation and student's interest in mathematics learning material are being affected after applying classroom flipped learning strategies with a scientific approach to class XI grade students of SMK 2 Padangpanjang? Are student's learning outcomes by applying classroom flipped strategies with the scientific approach are better than the one that does not apply that method? This study aims to describe student's learning outcomes, motivation, and interests in mathematics learning, and to see whether the experimental class learning outcomes are better than the control class. This research was conducted at SMK 2 Padang Panjang in the academic year 2017/2018. The sample is taken by using the random sampling technique which consisted of two sample groups, and each is consisted of 28 people. Based on the results of the study, it can be concluded that the student's mathematics learning outcomes are better than the previous one. In addition, student's motivation towards mathematics learning is in a high level and students' interests as well.
\end{abstract}

Keywords : Flipped classroom strategy, learning outcomes, motivation and interest.

This is an open access article distributed under the Creative Commons 4.0 Attribution License, which permits unrestricted use, distribution, and reproduction in any medium, provided the original work is properly cited. $@ 2019$ by author and Universitas Negeri Padang.

\section{PENDAHULUAN}

Pendidikan di sekolah pada saat ini dituntut untuk menghasilkan lulusan yang memiliki pemikiran kritis, kreatif dan mampu mensintesis serta merespon masalah lingkungan sosial yang kompleks ((Cortese, 2003; Wals \& Jickling, 2002). Salah strategi yang dapat digunakan adalah Flipped Classroom. Flipped Classroom adalah strategi pembelajaran cam puran yang membalikkan model pengajaran dan pembelajaran di dunia pendidikan secara tradisional (O'Flaherty \& Phillips, 2015). Ketika pembelajaran dengan strategi Flipped Class room, pembelajaran didaktik yang biasanya berlangsung selama waktu tatap muka, sebelumnya direkam dan disediakan bagi peserta didik untuk menonton sebelum kelas tatap muka, sementara kesempatan untuk memper dalam, memperluas dan menerapkan pema haman peserta didik tentang materi yang direkam adalah dengan cara strategi pembelajaran aktif di waktu pembelajaran di kelas (Cheng \& Weng, 2017; Roehl, Reddy, \& Shannon, 2013; Zainuddin \& Halili, 2016).

Premis kunci dari strategi Flipped Classroom adalah bahwa peserta didik terlibat dengan konten penting sebelum menghadiri kelas, sementara peluang untuk berpikir tingkat tinggi diberikan selama waktu pembelajaran di kelas (O'Flaherty \& Phillips, 2015). Sedangkan Bishop dan Verleger (2013) mendefinisikan strategi Flipped Classroom sebagai kegiatan pembelajaran kelompok interaktif di dalam kelas, dan mengarahkan instruksi individu berbasis komputer, misal Video ceramah, di luar kelas. Hal ini sesuai dengan definisi pembelajaran dengan strategi Flipped Class room yang diadopsi di FSE.

Banyak hasil penelitian telah menemukan bahwa pembelajaran dengan penerapan strategi Flipped Classroom dapat memberikan sejumlah keuntungan bagi guru dan peserta didik. Misalnya, menggunakan strategi pembelajaran aktif di kelas memungkinkan guru untuk memahami gaya dan kesulitan belajar peserta didik yang lebih baik; untuk menggunakan waktu kelas lebih efektif dan kreatif; dan untuk memenuhi kebutuhan pembelajaran kelompok peserta didik yang beragam sesuai dengan kurikulum dan memberikan bimbingan guru ke peserta didik yang dipersonalisasi dan kolaborasi antar rekan (Fulton, 2012; Roehl et al., 2013). Peserta didik juga merespon positif terhadap strategi Flipped Classroom, beberapa 
studi melaporkan bahwa pendekatan seperti itu lebih efektif dalam melibatkan peserta didik daripada pembelajaran tradisional di sekolah (Fulton, 2012; McCarthy, 2016; Nouri, 2016), dan memunculkan emosi positif dan sikap terhadap pembelajaran (Jeong, GonzálezGómez, \& Cañada-Cañada, 2016). Sedangkan Roehl et al. (2013) dan Vaughan (2014) berpendapat bahwa dizaman millenial sekarang ini, keterlibatan peserta didik dalam pembela jaran adalah pertimbangan yang lebih penting dari sebelumnya, dengan alasan bahwa generasi Millenial tidak lebih toleran daripada generasi lain terhadap pedagogi gaya pembelajaran tradisional.

Begitupula, Brent (dalamYahya,2014) mendefenisikan strategi Flipped Classroom sebagai pendekatan yang dapat diberikan oleh pendidik dengan cara meminimalkan jumlah instruksi langsung dalam praktek mengajar mereka sambil memaksimalkan interaksi antar peserta didik. Strategi Flipped Classroom ini memanfaatkan teknologi yang mendukung materi pembelajaran bagi peserta didik yang dapat di akses secara online. Pada pendekatan ini bahan pelajaran harus dipelajari oleh peserta didik di rumah sebelum pembelajaran. Pendidik sewaktu di dalam kelas tidak menjelaskan materi secara detail, tetapi hanya mereviu video yang sudah diberikan. Selanjutnya pendidik memberikan lembar diskusi kelompok (LDK).

Strategi Flipped Classroom dapat diterap kan di kelas dengan langkah-langkah:

1. Sebelum tatap muka, peserta didik diminta untuk belajar mandiri di rumah mengenai materi pertemuan berikutnya, dengan menonton video pembelajaran.

2. Pada pembelajaran di kelas, peserta didik dibagi menjadi beberapa kelompok yang terdiri dari 4 atau 5 orang perkelompok.

3. Peran pendidik pada saat pembelajaran berlangsung adalah memfasilitasi berlang sungnya diskusi atau sebagai fasilitator.

4. Pendidik memberikan kuis atau tes untuk mengukur pemahaman peserta didik terhadap materi pembelajaran.

Sementara hasil penelitian sebelumnya tentang strategi Flipped Classroom telah meng istimewakan pendapat peserta didik, daripada hasil penelitian yang berfokus pada pengalaman pendidik (lihat Bishop \& Verleger, 2013), atau menggunakan penyelidikan naratif sebagai cara untuk memperoleh pengalaman-pengalaman.
Pada saat penelitian ini dilakukan, disadari bahwa belum banyak studi yang menggunakan narasi untuk mengeksplorasi pengalaman pendidik dalam pembelajaran strategi Flipped Classroom di sekolah menengah (Huereca, 2015) dan setting pada pendidikan tinggi (Howitt \& Pegrum, 2015). Strategi Flipped Classroom menawarkan cara mengadaptasi model membalik pembelajaran biasa dengan cara yang responsif terhadap kebutuhan belajar peserta didik dan kesiapan peserta didik untuk suatu strategi Flipped Classroom.

Strategi pembelajaran aktif adalah kegiatan pembelajaran yang berpusat pada peserta didik yang mengharuskan peserta didik untuk 'melakukan sesuatu' dan berpikir dan merenungkan tentang apa yang mereka lakukan (Bonwell \& Eison, 1991; Misseyanni, Lytras, Papadopoulou, \& Marouli, \& 2018). Sejumlah teori dan metode pembelajaran yang berpusat pada peserta didik yang digunakan untuk memandu desain kegiatan di dalam kelas termasuk pembelajaran dengan tutor sebaya (bantuan rekan), pembelajaran kooperatif, pembelajaran berbasis masalah, pembelajaran kolaboratif (Bishop \& Verleger, 2013). Dengan cara ini, flipping learning "mewakili kombinasi unik dari teori-teori pembelajaran yang pernah dianggap tidak sesuai. Aktivitas pembelajaran berbasis masalah yang aktif yang dibangun di atas ideologi konstruktivis dan pengajaran instruksional yang berasal dari metode pengajaran langsung yang didasarkan pada prinsip behavioris" (Bishop \& Verleger, hlm. 1).

Pendekatan scientific merupakan pende katan dalam pembelajaran yang menuntut peserta didik beraktivitas sebagaimana seorang ahli sains yaitu dengan melakukan serangkaian aktivitas sesuai metode ilmiah. Ini sejalan dengan pendapat Yunus Abidin (2016) yang menyatakan bahwa pembelajaran dengan pendekatan scientifik merupakan pembelajaran yang menuntut peserta didik berpikir secara sistematis dan kritis dalam upaya memecahkan masalah yang bersifat analisis. Pembelajaran ini akan melibatkan peserta didik dalam kegiatan memecahkan masalah sesuai langkah-langkah metode ilmiah. Begitu pula, pengertian pendekatan scientific yang dirumuskan dalam kurikulum 2013 dan National Science Teacher Association (NSTA) adalah pendekatan scientific sebagai belajar/mengajar sains dan teknologi dalam konteks pengalaman manusia. 
Pendekatan scientific (scientific approach) dalam pembelajaran meliputi: merumuskan pertanyaan, merumuskan hipotesis, mengum pulkan data (informasi) untuk menyelesaikan masalah dengan berbagai teknik, mengasosiasi/ menganalisis data (informasi), dan menarik kesimpulan. Langkah selanjutnya adalah mengkomunikasikan hasil pembahasan. Lang kah-langkah tersebut dapat dilanjutkan dengan kegiatan mencipta atau menghasikan karya (Permendikbud No. 103 Tahun 2014).

Pembelajaran matematika dengan pene rapan strategi Flipped Classroom dengan pendekatan scientific diharapkan peserta didik secara aktif memberdayakan potensi yang ada dalam dirinya, untuk mengkontruksi pengeta huannya, selanjutnya pengetahuan yang sudah dimiliki peserta didik dapat diaplikasikan dalam menyelesaikan permasalahan matematika. Sete rusnya diharapkan peserta didik dapat berkarya, atau berwirausaha dengan pengetahuan yang sudah dimilikinya.

Permasalahan dalam penelitian ini adalah

1. Bagaimana hasil belajar matematika peserta didik dengan menerapkan strategi Flipped Classroom dengan pendekatan scientific pada peserta didik kelas XI SMKN 2 Padang Panjang?

2. Bagaimana motivasi belajar peserta didik setelah menerapkan strategi Flipped Class room dengan pendekatan scientific?

3. Bagaimana minat peserta didik terhadap materi pembelajaran matematika setelah mengikuti pembelajaran strategi flipped classroom dengan pendekatan scientific?

4. Apakah hasil belajar matematika peserta didik dengan penerapan strategi flipped classroom dengan pendekatan scientific lebih baik dari yang tidak menerapkan pada peserta didik kelas XI SMKN2 Padang Panjang?

\section{METODE PENELITIAN}

Jenis penelitian ini adalah penelitian eksperimen semu dengan desain penelitian adalah Randomized Control Group Posttest Only Design. Pada penelitian ini terdapat dua kelas yang masing-masing diambil secara random sampling, yaitu kelas eksperimen dan kelas kontrol. Kelas eksperimen dengan menggunakan dalam pembelajaran mengguna kan strategi flipped classroom dengan pendekatan scientific, sedangkan kelas kontrol menggunakan model pembelajaran yang diguna kan oleh guru di sekolah.

Populasi dalam penelitian ini adalah peserta didik kelas XI SMK N 2 Padang Panjang yang terdiri dari 8 lokal. Sedangkan sampel dalam penelitian ini adalah kelas XI TP 4 sebagai kelas eksperimen dan kelas XI TKJ 1 sebagai kelas kontrol. Teknik pengambilan sampel adalah teknik Cluster Sampling .

Variabel dalam penelitian ini adalah

1. $X_{1}=$ Hasil belajar matematika peserta didik pada ranah kognitif pada kelas eksperimen dengan penerapan strategi Flipped classroom dengan pendekatan scientific.

2. $X_{2}=$ Hasil belajar matematika peserta didik pada ranah kognitif pada kelas kontrol dengan tanpa penerapan strategi Flipped classroom dengan pendekatan scientific.

3. Motivasi dan Minat belajar peserta didik setelah penerapan strategi Flipped Class room dengan pendekatan scientific.

Jenis data pada penelitian ini adalah data primer dan data sekunder. Data primer dalam penelitian ini adalah hasil belajar, motivasi dan minat. Data primer diperoleh dari peserta didik kelas XI SMK N 2 Padang Panjang yang menjadi sampel. Sedangkan data sekunder pada penelitian ini adalah data jumlah peserta didik yang menjadi sampel serta data nilai ulangan harian 1 matematika peserta didik kelas XI SMK N 2 Padang Panjang. Data sekunder diperoleh dari guru matematika di kelas XI SMK N 2 Padang Panjang.

Instrumen yang digunakan sebagai alat pengumpul data adalah 1) Tes Hasil Belajar; Tes akhir yang diberikan adalah tes yang berbentuk essay yang telah memenuhi kriteri instrumen yang baik, 2) Angket motivasi terhadap pembelajaran, dan 3) Angket minat terhadap materi pembelajaran

Data penelitian yang dipakai pada penelitian ini adalah 1) data hasil belajar diperoleh melalui tes akhir, 2) data motivasi belajar dan minat terhadap materi pembelajaran. Data diperoleh dengan menyebarkan angket kepada peserta didik yang telah selesai mengikuti pembelajarannstrategi flipped class room dengan pendekatan scientific.

Analisis data hasil penelitian bertujuan untuk mengungkapkan hasil belajar kognitif, motivasi, dan minat peserta didik setelah menerapkan pembelajaran strategi Flipped Classroom dengan pendekatan scientific, serta untuk menganalisis kebenaran data hasil 
penelitian dilakukan uji hipotesis. Sebelum melakukan uji hipotesis, terlebih dahulu dahulu dilakukan uji normalitas dan uji homogenitas. Hasil uji normalitas menunjukkan bahwa kedua kelompok data berdistribusi normal, dan mempunyai variansi homogen.

Berdasarkan hasil uji normalitas dan homogenitas, data yang diperoleh berdistribusi normal dan homogen. Sehingga, uji hipotesis yang digunakan adalah perbedaan dua rerata atau uji-t. Kriteria pengujiannya adalah $\mathrm{H}_{0}$ diterima jika $t_{\text {hitung }}<t_{(\alpha) ;\left(n_{1}+n_{2}-2\right)}$ dan sebaliknya $\mathrm{H}_{0}$ ditolak jika $\mathrm{t}_{\text {hitung }} \geq \mathrm{t}_{(\alpha) ;\left(\mathrm{n}_{1}+\mathrm{n}_{2}-2\right)}$. Data Motivasi belajar dan minat diolah dengan menggunakan rumus

$$
\text { Nilai }=\frac{\text { skor perolehan }}{\text { skormax }} \times 5
$$

\section{HASIL DAN PEMBAHASAN}

\section{A. Hasil Penelitian}

Langkah- langkah Pembelajaran Strategi Flipped classroom dengan Pendekatan Scientific dapat dilihat pada Tabel 1.

Tabel1. Langkah- Langkah Strategi Flipped Classroom dengan Pendekatan Scientific

\begin{tabular}{|c|l|}
\hline No & $\begin{array}{l}\text { Langkah pembelajaran flipped classroom } \\
\text { dengan scientific approach }\end{array}$ \\
\hline 1 & \multicolumn{1}{|c|}{2} \\
2 & $\begin{array}{l}\text { Pendidik mereviu video pembelajaran yang } \\
\text { sudah diberikan kepada peserta didik. } \\
\text { Peserta didik menuliskan poin-poin materi } \\
\text { pembelajaran yang ada dalam video. }\end{array}$ \\
3 & $\begin{array}{l}\text { Peserta didik dibagi menjadi enam kelompok } \\
\text { yang terdiri dari empat orang. }\end{array}$ \\
5 & $\begin{array}{l}\text { Pendidik membagikan dua set LDK kepada } \\
\text { masing - masing kelompok. }\end{array}$ \\
5 & $\begin{array}{l}\text { Pendidik memberikan batas waktu untuk } \\
\text { penyelesaian permasalahan pada LDK. }\end{array}$ \\
7 & $\begin{array}{l}\text { Peserta didik untuk mempelajari LDK. } \\
\text { Peserta didik memahami permasalahan yang } \\
\text { ada pada LDK bersama teman kelompok. } \\
\text { Pendidik memberikan kesempatan untuk } \\
\text { menanyakan hal-hal yang belum dimengerti. }\end{array}$ \\
9 & $\begin{array}{l}\text { Peserta didik menyelesaikan permasalahan } \\
\text { yang ada pada LDK. } \\
\text { Perserta didik diminta untuk menggunakan } \\
\text { sumber belajar yang ada dalam mencari } \\
\text { informasi untuk menyelesaikan permasalahan. }\end{array}$ \\
11 & $\begin{array}{l}\text { Pendidik berkeliling pada setiap kelompok. } \\
\text { Pendidik memberikan bimbingan pada } \\
\text { kelompok yang membutuhkan. } \\
\text { Pendidik meminta perwakilan masing - } \\
\text { masing kelompok untuk mempresentasikan di } \\
\text { depan kelas hasil diskusi kelompoknya. }\end{array}$ \\
14 & $\begin{array}{l}\text { Pendidik meminta peserta didik dari kelompok } \\
\text { yang lain untuk menanggapi }\end{array}$ \\
\hline 13
\end{tabular}

\begin{tabular}{|c|l|}
\hline 1 & \multicolumn{1}{|c|}{2} \\
\hline 15 & $\begin{array}{l}\text { Pendidik mengulas kembali atau memberikan } \\
\text { penegasan apa yang telah disampaikan oleh } \\
\text { perwakilan kelompok. }\end{array}$ \\
16 & $\begin{array}{l}\text { Pendidik memberikan kuis. } \\
17\end{array}$ \\
18 & Pendidik memberikan video pembelajaran \\
& Di aktuk materi pertemuan selanjutnya. \\
& peserta didik untuk berdo'a.
\end{tabular}

a. Hasil belajar pada ranah kognitif

Nilai tertinggi $\left(\mathrm{X}_{\text {maks }}\right)$ dan nilai terendah $\left(\mathrm{X}_{\min }\right)$ serta persentase ketuntasan dari kedua kelas, seperti pada Tabel 2.

Tabel 2. Data Perhitungan Tes Akhir

\begin{tabular}{|c|c|c|c|c|c|}
\hline Kelas & $\mathrm{N}$ & $\bar{x}$ & $\mathrm{X}_{\text {maks }}$ & $\mathrm{X}_{\min }$ & $\begin{array}{c}\% \\
\text { Ketuntasan }\end{array}$ \\
\hline Eksperimen & 30 & 72,00 & 100 & 38,57 & 53,33 \\
\hline Kontrol & 32 & 63,66 & 100 & 38,57 & 33,33 \\
\hline
\end{tabular}

Pada Tabel 2 terlihat bahwa hasil belajar peserta didik kelas eksperimen lebih tinggi daripada kelas kontrol. Begitupula tingkat ketuntasan belajar matematika peserta didik, kelas eksperimen lebih banyak dari kelas kontrol.

b. Deskripsi motivasi dan minat

Berdasarkan hasil olahan data motivasi dan minat belajar, diperoleh data seperti Tabel 3 .

Tabel 3 : Data Perhitungan Kelas Eksperimen

\begin{tabular}{lccccc} 
Data angket & $\mathrm{N}$ & $\bar{x}$ & $\mathrm{X}_{\text {maks }}$ & $\mathrm{X}_{\text {min }}$ & Ket \\
\hline $\begin{array}{l}\text { Motivasi terhadap } \\
\text { Pembelajaran }\end{array}$ & 28 & 130,7 & 158 & 97 & $\begin{array}{c}\text { Rata- } \\
\text { rata } \\
\text { tinggi }\end{array}$ \\
\hline $\begin{array}{l}\text { Minat Terhadap } \\
\text { materi }\end{array}$ & 28 & 129,4 & 158 & 98 & $\begin{array}{c}\text { Rata- } \\
\text { rata } \\
\text { tinggi }\end{array}$ \\
\hline
\end{tabular}

Pada Tabel 3 terlihat bahwa motivasi terhadap pembelajaran matematika dan minat terhadap materi ajar pada kelas eksperimen ratarata tinggi, yakni 130,7 dan 129,4.

\section{B. Pembahasan}

1. Hasil belajar matematika ranah kognitif

Berdasarkan analisis data tes akhir menunjukkan bahwa hasil belajar peserta didik kelas eksperimen lebih baik dari pada hasil belajar matematika peserta didik pada kelas kontrol di kelas XI SMKN 2 Padangpanjang. Hal ini berarti pembelajaran dengan menggunakan strategi flipped classroom dengan pendekatan scientific lebih baik dari pada tanpa menggunakan strategi flipped classroom dengan pendekatan scientific. 
Proses pembelajaran di kelas eksperimen selalu diberikan Lembar Diskusi Kelompok (LDK) yang berguna untuk membantu peserta didik dalam memahami materi dan mengerjakan tugas selama menggunakan strategi flipped classroom dengan pendekatan scientific. Ketika belajar berkelompok dengan strategi flipped classroom dengan pendekatan scientific hampir semua peserta didik bersemangat untuk mengerjakan LDK. Hal ini sesuai dengan Hanson (2006) yang menyatakan bahwa dengan adanya LDK peserta didik bekerjasama dalam membangun pemahaman dan pengetahuannya, sehingga peserta didik lebih mudah mengingat dan mengerti, serta pembelajaran menjadi lebih efektif ketika peserta didik saling bekerja sama dengan banyak berdiskusi baik didalam kelompok maupun antar kelompok.

Kuatnya informasi yang melekat pada memori peserta didik, akan berdampak pula terhadap perolehan hasil belajar peserta didik. Disamping itu, peserta didik dapat belajar memecahkan masalah secara obyektif, kritis, terbuka dan kerja sama. Hal ini akan memberikan pengaruh terhadap sikap ilmiah, keterampilan serta hasil belajar peserta didik (Dewi dkk, 2013).

Proses pembelajaran pada kelas yang menerapkan strategi Flipped Classroom dengan pendekatan scientific ini membuat peserta didik lebih termotivasi dalam belajar karena terdapat variasi dalam proses pembelajaran. Hal ini sejalan dengan temuan Fulton, 2012; McCarthy, 2016; Nouri, 2016) dan Jeong, GonzálezGómez, \& Cañada-Cañada, 2016), yakni peserta didik merespon positif terhadap strategi Flipped Classroom dan lebih efektif dalam melibatkan peserta didik daripada pembelajaran tradisional di sekolah (Fulton, 2012; McCarthy, 2016; Nouri, 2016), serta dapat memunculkan emosi positif dan sikap terhadap pembelajaran.

Hasil tes akhir menunjukkan bahwa hasil belajar matematika peserta didik kelas eksperimen lebih baik dari pada kelas kontrol. Hal ini terlihat pada nilai rata-rata kelas eksperimen adalah 72,00 dan persentase ketuntasan mencapai 53,33\% sedangkan nilai rata-rata kelas kontrol adalah 63,66 dan persentase ketuntasan mencapai 33,33\%. Ini menunjukkan bahwa tingkat pemahaman peserta didik kelas eksperimen terhadap materi pembelajaran lebih baik dari pada peserta didik kelas kontrol. Sehingga penerapan strategi flipped classroom dengan pendekatan scientific dapat meningkatkan hasil belajar matematika peserta didik. Hal ini juga dapat dilihat dari uji yang digunakan dalam analisis hipotesis adalah uji-t dengan taraf kepercayaan $95 \%$ atau $\alpha=0.05$, diperoleh bahwa pembelajaran dengan strategi flipped classroom dengan pendekatan scientific lebih baik daripada hasil belajar matematika peserta didik tanpa menerapkan strategi flipped classroom dengan pendekatan scientific pada peserta didik kelas XI SMKN 2 Padang Panjang tahun pelajaran 2017/2018.

\section{Motivasi Belajar dan Minat Terhadap Materi Pelajaran}

Motivasi peserta didik setelah mengikuti pembelajaran Flipped Classrom, tergolong tinggi baik motivasi terhadap pembelajaran maupun motivasi peserta didik terhadap materi pembelajaran. Angket tentang motivasi terhadap pembelajaran terdiri dari 36 item, telah diisi peserta didik dengan lengkap. Skor setiap item,pada umumnya menunjukkan motivasi yang tinggi dari peserta didik. Seperti item pertama menyatakan kepuasan peserta didik terhadap pembelajaran yang dilaksanakan guru. Dari 28 peserta didik, 9 orang menyatakan sangat puas, 9 orang puas, dan 10 orang menyatakan cukup puas. Item kedua, menyatakan kesenangan peserta didik terhadap pembelajaran. Dari 28 peserta didik, 5orang sangat senang, 14 orang senang, dan 7 orang cukup, dan 2 orang tidak ada respon. Item ke 25 menyatakan keyakinan peserta didik akan berhasil dalam pembelajaran. Dari 28 peserta didik, 11 orang sangat tinggi keyakinannya, 9 orang tergolong tinggi, 7 orang cukup,dan lorang tidak yakin.

Minat terhadap materi pembelajaran, ratarata juga tergolong tinggi. Item untuk minat terhadap materi pembelajaran ada 34 item. Item pertama menyatakan, peserta didik mudah mempelajari materi pembelajaran. Dari 28 peserta didik, 6 orang menyatakan sangat mudah, 7 orang menyatakan mudah, 9 orang menyatakan cukup, dan 6 orang menyatakan agak sulit. Item kedua menyatakan materi pembelajaran sulit. Dari 28 peserta didik, 3orang menyatakan sangat sulit, 5 orang sulit, 8 orang menyatakan cukup sulit, 10 orang menyatakan mudah, dan 2 orang menyatakan sangat mudah. Item ketiga, menyatakan keyakinan peserta didik dapat mengikuti pembelajaran dengan baik. Dari 28 peserta didik, 5 orang menyatakan sangat yakin, 18orang yakin, 3 orang cukup 
yakin, dan 2 orang kurang yakin. Item ke 27 menyatakan keyakinan peserta didik untuk berhasil dalam pembelajaran. Dari 28 orang, 10 menyatakan sangat yakin, 14 orang menyatakan yakin, 1 orang menyatakan cukup yakin, dan 3 orang menyatakan tidak yakin. Item ke 31 menyatakan, rasa kecewa dengan pembelajaran. Dari 28 peserta didik, 12 Orang menyatakan tidak kecewa, 12 orang kecewa, dan 4 orang sangat kecewa.

Persentase untuk minat peserta didik terhadap materi pelajaran adalah: Sangat tinggi $11 \%$, tinggi $54 \%$, cukup $21 \%$, dan kurang $14 \%$. Berarti $11 \%$ dari perseta didik punya minat yang sangat tinggi terhadap materi pembelajaran yang ditampilkan dengan video pembelajaran. Kemudian $54 \%$ dari peserta didik punya minat yang tinggi.

Persentase untuk motivasi peserta didik terhadap pembelajaran adalah: untuk kategori sangat tinggi $25 \%$, tinggi $39 \%$, cukup $32 \%$, dan kurang $4 \%$. Dengan demikian berarti $25 \%$ dari peserta didik punya motivasi yang sangat tinggi untuk mengikuti pembelajaran dengan strategi Flipped Classroom dengan pendekatan scientific, $39 \%$ tergolong tinggi. Berarti sebahagian besar peserta didik termotivasi untuk mengikuti pembelajaran.

\section{KESIMPULAN}

Berdasarkan hasil penelitian dan pembahasan dapat disimpulkan bahwa

1. Hasil belajar matematika peserta didik yang menerapkan pembelajaran dengan strategi Flipped Classroom dengan pendekatan scientific lebih baik daripada hasil belajar matematika peserta didik yang tanpa menerapkan pada peserta didik kelas XI SMKN 2 Padang Panjang.

2. Motivasi peserta didik terhadap pembela jaran dengan penerapan strategi Flipped Classroom dan pendekatan scientific tergolong tinggi.

3. Minat peserta didik terhadap materi pembelajaran matematika dengan strategi strategi Flipped Classroom dan pendekatan scientific juga tergolong tinggi.

\section{UCAPAN TERIMAKASIH}

Penulis mengucapkan terimakasih kepada Lembaga Penelitian dan Pengabdian Masyarakat (LP2M) Universitas Muhamadiyah Sumatera Barat, dan Dekan FKIP UMSB.
Penulis juga mengucapan terimakasih kepada Ketua Prodi Pendidikan Matematika, guru bidang studi Matematika SMK N 2 Padang Panjang, serta semua pihak yang telah membantu dalam penyelesaian penelitian dan penyusunan artikel ini.

\section{DAFTAR PUSTAKA}

Aydın, B. 2016. The effects of flipped classroom model on academic achievement, homework/task stress level and transfer of learning. Unpublished master thesis, Süleyman Demirel University, Isparta.

Adhitiya, E N, A Prabowo, and R Arifudin. 2015. "Studi Komparasi Model Pembelajaran Traditional Flipped Dengan Peer Instruction Flipped Terhadap Kemampuan Pemecahan Masalah." Unnes Journal of Mathematics Education 4(2): hal. 17-26.

Arikunto, Suharismi. 2013. Dasar - Dasar Evaluasi Pendidikan”. Jakarta : Bumi Aksara.

Arikunto, Suharismi. 2010. Prosedur Penelitian. Yogyakarta: Rineka Cipta.

Baepler, P., Walker, J. D., \& Driessen, M. 2014. It's not about seat time: Blending, flipping, and efficiency in active learning classrooms. Computers \& Education, 78, 227-236.

https://doi.org/10.1016/j.compedu.2014.0 6.006.

Bell, M. R. 2015. An investigation of the impact of a flipped classroom instructional approach on high school students' content knowledge and attitudes toward the learning environment. Unpublished master thesis, Brigham Young University, Utah.

Bishop, J. L., \& Verleger, M. A. 2013. The flipped classroom: A survey of the research. In ASEE National Conference Proceedings, Atlanta, GA (Vol. 30, No. 9, pp. 1-18).

Bonwell, C. C., \& Eison, J. A. 1991. Active Learning: Creating Excitement in the Classroom. ASHE-ERIC Higher Education Report No. 1. Washington D.C.: The George Washington University, School of Education and Human Development.Bolat, Y. 2016. The flipped classes and education information 
network (EIN). Journal of Human Sciences, 13 (2), 3373-3388.

Çakır, E. 2017. The effect of flipped classroom on 7th grade students' academic achievemnt, cognitive risk taking skills and computational thinking skills in science education classroom. Unpublished master thesis, On Dokuz Mayıs University, Samsun.

Cheng, Y., \& Weng, C. 2017. Factors influence the digital media teaching of primary school teachers in a flipped class: A Taiwan case study. South African Journal of Education, 37(1), 1-12. https://doi.org/10.15700/saje.v37n1a1293.

Cortese, A. D. 2003. The critical role of higher education in creating a sustainable future. Planning for Higher Education, 31(3), 15-22.

Daryanto. 2014. Pendekatan Pembelajaran Saintifik Kurikulum 2013. Yogyakarta: Gava Media.

Dewi, N.L., Dantes, N.,\&Sadia,I.W. 2013. Pengaruh Model Pembelajaran Inkuiri terbimbing terhadap sikap Ilmiah dan Hasil Belajar IPA. Pendasi: Jurnal Pendidikan Dasar Indonesia, 3(1).

Dimyati dan Mudjiono. 2006 "Belajar dan Pembelajaran". Jakarta : PT. Rineka Cipta.

Fulton, K. 2012. Upside down and inside out: Flip your classroom to improve student learning. Learning \& Leading with Technology, 39(8), 12-17.

Hamdani. 2011. Strategi Belajar Mengajar. Bandung : Pustaka Setia.

Haryanti, Francisca. 2016. Peran Teknologi Dalam Flipped Classroom". Dinama Teknologi $16 \mathrm{Vol} 8$.

Herron, J.D., Luis, L., Cantu, Richard, W., \& Venu, S. (1977). Problems Associated with Concept Analysis. Science Education, 61(2), 185-199.

Huereca, K. 2015. High school mathematics teachers' connective knowledge of the challenges and possibilities in implementing the flipped learning model: An embedded mixed-methods study. Published dissertation: The University of Texas at El Paso.

Janssen, Fred J. J. M., Hanna B. Westbroek and Jan H. van Driel. (2014). How to Make Guided Discovery Learning Practical for Student Teachers. Instr Sci, 42,67-90.
Jeong, J. S., González-Gómez, D., \& CañadaCañada, F. (2016). Students' perceptions and emotions toward learning in a flipped general science classroom. Journal of Science Education and Technology, 25(5), 747-758. https://doi.org/10.1007/s10956016-9630-8.

Kemendikbud. 2016. Silabus Mata Pelajaran Sekolah Menengah Atas/Madrasah Aliyah (SMA/MA) Mata Pelajaran Matematika. Jakarta: Kementrian Pendidikan dan Kebudayaan.

Kemendikbud. 2014. Implementasi Kurikulum 2013 Mata Pelajaran Matematika SMP/MTs". Jakarta: Kemendikbud.

Misseyanni, A., Lytras, M. D., Papadopoulou, P., \& Marouli, C. (2018). Introduction. In A. Misseyanni, M. D. Lytras, P. Papadopoulou, \& C. Marouli (Eds.), Active Learning Strategies in Higher Education: Teaching for Leadership, Innovation, and Creativity, (pp. 1-13). United Kingdom: Emerald Publishing Limited.

Nur Fitriyana Ulfa, Budi Murtiyasa. 2014. Implementasi Strategi Flipped classroom Dalam Pembelajaran Matematika Terhadap Kemampuan Kognitif Ditinjau Dari Keaktifan Belajar Peserta didik SMA Negeri 1 Surakarta".

O'Flaherty, J., \& Phillips, C. 2015. The use of flipped classrooms in higher education: A scoping review. Internet and Higher Education, 25, 85-95.

https://doi.org/10.1016/j.iheduc.2015.02.0 02 .

Roehl, A., Reddy, S. H., \& Shannon, G. J. (2013). The flipped classroom: An opportunity to engage millennial students through active learning strategies. Journal of Family and Consumer Sciences, 105(2), 44-49.

Roth, K. 2014. Elementary science teaching. In N. Lederman, \& S. Abell (Eds.), Handbook of research on science education, (vol. 2, pp. 361-394). New York: Routledge.

Sudjana, Nana. 2013. Penilaian Hasil Proses Belajar Mengajar. Bandung: PT Remaja Rosdakarya.

Sudjana. 2005. Metode Statistik. Bandung: PT. Tarsito.

Sugiyono. 2007. "Metode Penelitian Pendidikan". Bandung: Alfabeta. 
Suryabrata, Sumadi. 2011. "Metodologi Penelitian". Yogyakarta: PT. Raja Grafindo Persada.

Suyahya, Indra. 2014. Efektifitas Pelaksanaan Strategi Pembelajaran Flipped classroom Dengan Memanfaatkan Media Pembelajaran Software Pesona Edu Dalam Meningkatkan Prestasi Belajar Sisiwa Di SMP Jakarta." Seminar Nasional Hasil-hasil Penelitian (20): 8692.

Talbert, R. 2017. Flipped learning: A guide for higher education faculty. Virginia: Stylus Publishing.

Vaughan, M. 2014. Flipping the learning: An investigation into the use of the flipped classroom model in an introductory teaching course. Education Research and Perspectives (Online), 41, 25.
Wals, A. E., \& Jickling, B. 2002. "Sustainability" in higher education: From doublethink and newspeak to critical thinking and meaningful learning. International Journal of Sustainability in Higher Education, 3(3), 221-232. https://doi.org/10.1108/146763702104346 88.

Zainuddin, Z. \& Halili, S. H. 2016. Flipped classroom research and trends from different fields of study. International Review of Research in Open and Distributed Learning, 17 (3), 313-340. 